\title{
Template-Free Nanostructured Fluorine-Doped Tin Oxide Scaffolds for Photoelectrochemical Water Splitting
}

\author{
Ivan Garcia-Torregrosa, ${ }^{\dagger}$ Jochem H. J. Wijten, ${ }^{\dagger}$ Silvia Zanoni, ${ }^{\dagger}$ Freddy E. Oropeza, ${ }^{\ddagger}$ Jan P. Hofmann, ${ }^{\ddagger}$
} Emiel J. M. Hensen, ${ }^{+0}$ and Bert M. Weckhuysen*, ${ }^{*}$

\begin{abstract}
${ }^{\dagger}$ Inorganic Chemistry and Catalysis Group, Debye Institute for Nanomaterials Science, Faculty of Science, Utrecht University, Universiteitsweg 99, 3584 CA Utrecht, The Netherlands

${ }^{\ddagger}$ Laboratory for Inorganic Materials and Catalysis, Department of Chemistry and Chemical Engineering, Eindhoven University of Technology, P.O. Box 513, 5600 MB Eindhoven, The Netherlands
\end{abstract}

\section{Supporting Information}

ABSTRACT: The synthesis and characterization of highly stable and conductive $\mathrm{F}: \mathrm{SnO}_{2}$ (FTO) nanopyramid arrays are investigated, and their use as scaffolds for water splitting is demonstrated. Current densities during the oxygen evolution reaction with a $\mathrm{NiFeO}_{x}$ catalyst at $2 \mathrm{~V}$ vs reversible hydrogen electrode were increased 5-fold when substituting commercial FTO (TEC 15) by nanostructured FTO scaffolds. In addition, thin $\alpha$ - $\mathrm{Fe}_{2} \mathrm{O}_{3}$ films ( $\sim 50 \mathrm{~nm}$ thick) were employed as a proof of concept to show the effect of our nanostructured scaffolds during photoelectrochemical water splitting. Doublelayer capacitance measurements showed a drastic increase of the relative

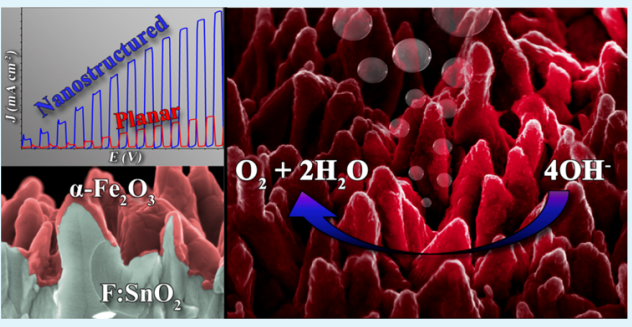
electrochemically active surface area for the nanostructured samples, in agreement with the observed photocurrent enhancement, whereas UV-vis spectroscopy indicates full absorption of visible light at wavelengths below $600 \mathrm{~nm}$.

KEYWORDS: nanostructuring, spray pyrolysis, water splitting, photoelectrode, spectroscopy

\section{INTRODUCTION}

Inexpensive and stable metal-oxide semiconductors capable of absorbing visible light to drive the water splitting reaction have gained special interest from the scientific community in the past few years. ${ }^{1-4}$ However, metal-oxide semiconductors suffer from significant losses due to their high bulk recombination of charges generated by light absorption, a consequence of their relatively low charge carrier mobility and short diffusion lengths. ${ }^{3-5}$ Although doping can show an increase in the number of charge carriers of more than 1 order of magnitude, ${ }^{3}$ low hole diffusion lengths, usually on the order of a few nanometers, ${ }^{5}$ compared to the usual light penetration depth, on the order of $100 \mathrm{~nm}$ for visible light, ${ }^{6}$ lead to the absorption of the majority of photons in the bulk and far from the space charge layer. ${ }^{7}$ Therefore, the vast majority of photogenerated charge carriers do not contribute effectively to the water splitting reaction. To tackle this intrinsic limitation, several nanostructuring approaches were shown to further improve the dynamics of photogenerated charges enhancing the final photocurrents. $^{8-11}$ For instance, Kay et al. ${ }^{12}$ obtained a significant increase in photocurrent to a value of $2.2 \mathrm{~mA}$ / $\mathrm{cm}^{2}$ at $1.23 \mathrm{~V}$ vs reversible hydrogen electrode (RHE) and $42 \%$ incident photon-to-current conversion efficiency (IPCE) at $370 \mathrm{~nm}$ by optimizing the nanostructure of hematite $(\alpha$ $\left.\mathrm{Fe}_{2} \mathrm{O}_{3}\right)$ doped with $\mathrm{Si}$. Nevertheless, despite the promising performance of nanostructured hematite thin films, quantum conversion efficiencies remained relatively low $(<20 \%)$ in the absorbance region between 450 and $600 \mathrm{~nm}$, where the solar spectrum is peaking.

A potential strategy to enhance the performance of metaloxide photoelectrodes could involve the design of thin-film semiconductors with thicknesses in the range of the space charge layer to fully utilize the photogenerated charges for the water splitting reaction. In other words, host-guest architectures where a very thin film of a light-absorbing semiconductor (guest or absorber) is deposited onto a nanostructured current collector (host or scaffold) could help decoupling charge transport and light harvesting while at the same time increasing the surface area of the photoelectrode. Following this strategy, Sivula et al. ${ }^{13}$ observed a $20 \%$ increase in photocurrents for a host-guest system comprising $\alpha-\mathrm{Fe}_{2} \mathrm{O}_{3}$ (guest) and $\mathrm{WO}_{3}$ (host). Similarly, Müller et al. ${ }^{14}$ reported an increase in the charge transfer efficiency of $88 \%$ when an inverse opal $\mathrm{WO}_{3}$ scaffold was spin-coated with $\mathrm{Sn}$-doped $\alpha-\mathrm{Fe}_{2} \mathrm{O}_{3}$. In the same line, antimony-doped tin oxide and indium-doped tin oxide inverse opals were also employed as scaffolds rendering similar results. ${ }^{15-17}$ A recent report from Jaramillo's group exhibited a template-assisted ion milling technique for the top-down formation of nanopillars on commercial fluorine-doped tin oxide (FTO) samples providing a $40 \%$ enhancement of the final photocurrents when compared

Received: March 26, 2019

Accepted: September 16, 2019

Published: September 16, 2019 
to the planar counterpart in $\mathrm{WO}_{3}$ photoanodes deposited by atomic layer deposition (ALD). ${ }^{18}$ Although this work represents a very promising proof of concept, the relatively low aspect ratio of the nanopillars (roughness factor was 1.4 times over native FTO) in the resulting scaffold and the complexity of the milling process are the main drawbacks of this top-down approach.

The fabrication of high-quality FTO thin films by different methods, such as magnetron sputtering or air blast spray pyrolysis, has attracted much attention in recent years. ${ }^{19-21}$ Moreover, the synthesis of nanostructured $\mathrm{SnO}_{2}$ arrays by chemical vapor deposition (CVD) for sensing applications was also reported. ${ }^{22-25}$ However, the incorporation of fluorine species in the structure of cassiterite $\mathrm{SnO}_{2}$ has proven to be more challenging. ${ }^{26-29}$ Motivated by the computational study of Wang et al., ${ }^{30}$ demonstrating the potential benefits of highaspect-ratio scaffolds, we have developed in our lab a novel lateral ultrasonic spray pyrolysis (USP) method, also known as aerosol-assisted chemical vapor deposition (AACVD), for the preparation of template-free, highly conductive, and highaspect-ratio FTO nanopyramids for use as nanostructured scaffolds in photoelectrochemical applications. The main advantages of USP strive in its simplicity and wider choice and availability of precursors together with high deposition rates and precise stoichiometry control. Figure S1 shows a schematic model of the nanoarchitecture, where a thin hematite coating acts as a light absorber, whereas FTO serves as a current collector and nanostructured scaffold. To demonstrate the feasibility of our new synthesis approach and serving as proof of concept, bare hematite thin films of ca. $50 \mathrm{~nm}$ thickness were deposited by vertical USP onto commercial FTO (TEC 15) and our nanostructured FTO (three-dimensional (3D)-FTO), and their oxygen evolution reaction (OER) performance under simulated 1 sun front illumination was compared.

To the best of our knowledge, this is the first time that a template-free, high-aspect-ratio nanostructured FTO scaffold prepared by USP has been employed as a photoanode substrate for photoelectrochemical water splitting. The simplicity and high reproducibility of this fabrication process offer new possibilities for the design of other metal-oxide photoelectrodes where the photogenerated charge collection and light absorbance can be optimized to match the thickness of the space charge layer while maintaining high light absorption.

\section{EXPERIMENTAL SECTION}

2.1. Chemicals. In the preparation of tin precursor solutions, 13.4 mmol $\mathrm{SnCl}_{4} \cdot\left(\mathrm{H}_{2} \mathrm{O}\right)_{x}$, Alfa Aesar (98\% pure), was dissolved in a mixture composed of $3 \mathrm{~mL}$ of acetone and $47 \mathrm{~mL}$ of deionized (DI) water and stirred for $30 \mathrm{~min}$. Then, different amounts of $\mathrm{NH}_{4} \mathrm{~F}$, Alfa Aesar, ACS ( $98 \%$ pure), ranging from 25 to $40 \mathrm{mmol}$ were added to the solution and stirred for another $30 \mathrm{~min}$. To adjust the $\mathrm{pH}$ to 0,10 $\mu \mathrm{L}$ of concentrated $\mathrm{HCl}$, Sigma-Aldrich (37\%), was added to $10 \mathrm{~mL}$ of DI water and mixed with the solution during stirring.

For the preparation of the iron precursor, 1 mmol $\mathrm{Fe}\left(\mathrm{C}_{5} \mathrm{H}_{7} \mathrm{O}_{2}\right)_{3}$ (iron acac), Acros Organics (99\% pure), was dissolved in $50 \mathrm{~mL}$ of dimethylformamide, Fisher Scientific ( $99 \%$ pure), and stirred overnight. $\mathrm{NaOH}$ (99\%), Emsure, was used to adjust the $\mathrm{pH}$ in the photoelectrochemical cell.

Commercial FTO-coated glass (Pilkington, TEC 15) and opticalgrade fused silica $(2 \mathrm{~mm})$ slides with dimensions of $30 \times 15 \mathrm{~mm}^{2}$ were employed as substrates for the deposition of 3D-FTO and hematite. Prior to their use, each slide was mechanically cleaned with abrasive detergent (CIF cream, Unilever) twice and immersed in a mixture of ethanol, acetone, and water and then placed in an ultrasound bath $(45 \mathrm{kHz}$ and $100 \mathrm{~W})$ for $15 \mathrm{~min}$. Afterward, the solution was changed for $1 \mathrm{M} \mathrm{HCl}$ followed by another $15 \mathrm{~min}$ ultrasound bath step and then another $15 \mathrm{~min}$ in DI water. Finally, the slides were dried with $\mathrm{N}_{2}$ and placed in a UV/ozone procleaner (Bioforce) for $15 \mathrm{~min}$.

2.2. Materials Synthesis. For the synthesis of the 3D-FTO films, a home-built setup provided with a ceramic piezoelectric atomizer operating at $20 \mathrm{Watt}$ and $1.6 \mathrm{MHz}$ was employed. To study the effect of the substrate on the film growth, commercial FTO TEC-15-coated soda lime glass and optical-grade fused silica were used as substrates. As the carrier gas, a continuous flow of compressed air was adjusted, varying the flow rates from 2 to $6 \mathrm{~L} / \mathrm{min}$. The scheme in Figure S2 describes the main components of the horizontal USP setup.

The glass substrates were placed on top of a spinning Ti disc (2 rpm), which was directly in contact with a molten tin alloy. In this way, each substrate was exposed to the precursor mist at a minimum distance from the nozzle of $1.5 \mathrm{~cm}$ during $10 \mathrm{~s}$ for every minute of the reaction time. The studied substrate temperature was varied from 450 to $550{ }^{\circ} \mathrm{C}$ at intervals of $25{ }^{\circ} \mathrm{C}$. Due to the 20 Watt ultrasound generator being immersed in the atomized solution, the temperature of the solution was kept constant at $23{ }^{\circ} \mathrm{C}$ by placing the atomization unit in a cooling water device. The finely atomized aerosol was then carried to the reaction chamber through a Teflon tube measuring 20 $\mathrm{mm}$ in inner diameter and $170 \mathrm{~mm}$ in length. The reaction duration was studied from 5 to $40 \mathrm{~min}$. The as-prepared samples were subjected to a cleaning procedure similar to the one described for commercial FTO and fused silica glass to remove the presence of unreacted species and carbon deposits from the surface of the nanopyramids.

Conformal hematite coatings were deposited on 3D-FTO and commercial FTO following a vertical USP configuration employing a Sonaer narrow spray atomizer nozzle $(60 \mathrm{kHz})$ coupled with a vortex spray shaper unit. In this case, to decrease the film roughness, the iron acac solution concentration was kept at $20 \mathrm{mM}$ and the carrier gas flow was $4 \mathrm{~L} / \mathrm{min}$. The substrate temperature was $450{ }^{\circ} \mathrm{C}$ in every case, and the number of USP cycles was 120 , rendering film thicknesses of about $\sim 45 \mathrm{~nm}$. After deposition, the samples were heattreated at $550{ }^{\circ} \mathrm{C}$ for $2 \mathrm{~h}$ and $750{ }^{\circ} \mathrm{C}$ for 15 min with a heating ramp of $15{ }^{\circ} \mathrm{C} / \mathrm{min}$ and cooling down naturally to room temperature.

2.3. Material Characterization. UV-vis spectroscopy measurements were carried out using a UV-vis-NIR LAMBDA 950S (PerkinElmer) spectrophotometer equipped with a double beam in the transmission mode to allow for simultaneous collection of baseline and the sample spectra. Both transmission and diffuse reflection spectra were recorded from 800 to $350 \mathrm{~nm}$.

$\mathrm{X}$-ray diffraction (XRD) patterns were acquired from 20 to $80^{\circ} 2 \theta$ angles using a D2 (Bruker) diffractometer equipped with a Co K $\alpha \mathrm{X}$ ray source excited at $30 \mathrm{kV}$ and $10 \mathrm{~mA}$. The acquisition conditions for the diffractograms were $0.04^{\circ}$ step size and $1 \mathrm{~s}$ integration time.

Scanning electron microscopy (SEM) images showing surface morphology and cross section thickness were taken using an FEI Helios Nanolab 600 FIB-SEM instrument at $5 \mathrm{kV}$ acceleration voltage after focus ion beam (FIB) milling of the sample.

X-ray photoelectron spectroscopy (XPS) on the 3D-FTO and hematite-coated 3D-FTO was carried out on a K- $\alpha$ XP spectrometer (Thermo Scientific) equipped with a monochromatic small-spot (400 $\mu \mathrm{m})$ X-ray source operating at $72 \mathrm{~W}$, a $180^{\circ}$ double focusing hemispherical analyzer with a 128-channel delay line detector, and an $\mathrm{Al}$ anode $[E(\mathrm{Al} \mathrm{K \alpha})=1486.6 \mathrm{eV}]$. High-resolution spectra of core levels (C 1s, O 1s, Sn 3d, Fe 2p, and Fe 3p) and wide-range survey spectra were recorded with pass energies of 50 and $200 \mathrm{eV}$, respectively. Binding energy (BE) calibration of the spectra was done by setting the $\mathrm{C} 1 \mathrm{~s}$ peak of $\mathrm{sp}^{3}$ adventitious carbon to $284.8 \mathrm{eV}$. Spectra were fitted using CasaXPS software.

2.4. Electrochemical Measurements. Photoelectrochemical measurements were performed using an Ivium CompactStat.h10800 potentiostat with a Pt coil as the counter electrode and saturated $\mathrm{Ag}$ / $\mathrm{AgCl}$ reference electrode in $1 \mathrm{M} \mathrm{NaOH}$ electrolyte solution. A Zahner 
PECII model with $1 \mathrm{~cm}^{2}$ of the sample exposed to the electrolyte was employed as the photoelectrochemical cell. Front side illumination of the samples was provided using a solar simulator Oriel Sol3A $450 \mathrm{~W}$ with $101 \times 101 \mathrm{~mm}^{2}$ beam size calibrated to 1 sun $\left(100 \mathrm{~mW} / \mathrm{cm}^{2}\right)$. Online gas chromatography (GC) was obtained using a Global Analyzer Solutions Compact GC 4.0 (Interscience). $\mathrm{O}_{2}$ was injected via a $50 \mu \mathrm{L}$ loop and analyzed on a TCD. An injection was done each minute using $\mathrm{Kr}$ as an internal standard. IPCE tests were performed on a Zahner cIMPS workstation using a multicolor LED excitation source.

\section{RESULTS AND DISCUSSION}

3.1. Material Synthesis and Characterization. Several parameters in the bottom-up synthesis method explored were studied for the preparation of nanostructured vertical FTO arrays. Keeping the $\mathrm{SnCl}_{4}$ and $\mathrm{NH}_{4} \mathrm{~F}$ concentrations fixed at 0.2 and $0.5 \mathrm{M}$, respectively, variations of the temperature, carrier gas flow, and reaction time led to very different morphologies in the final samples. In Figure S3, scanning electron microscopy (SEM) images of three 3D-FTO samples prepared at $450{ }^{\circ} \mathrm{C}(\mathrm{a}$ and $\mathrm{b}), 500{ }^{\circ} \mathrm{C}$ (c and d), and $550{ }^{\circ} \mathrm{C}$ (e and f) clearly show the impact of the substrate temperature on the grain growth. At temperatures of $450{ }^{\circ} \mathrm{C}$ and below, large grains between $500 \mathrm{~nm}$ and $1 \mu \mathrm{m}$ are formed, whereas by increasing the temperature to $500{ }^{\circ} \mathrm{C}$, the average grain size dropped to the range of $200-450 \mathrm{~nm}$.

Figure 1 shows the X-ray diffractograms of commercial TEC $15 \mathrm{FTO}$, the $3 \mathrm{D}$-FTO material prepared at $450{ }^{\circ} \mathrm{C}$, the $3 \mathrm{D}$ -



Figure 1. X-ray diffractograms of commercial TEC 15 FTO (black line), 3D-FTO prepared at $450{ }^{\circ} \mathrm{C}$ (red line), 3D-FTO prepared at $500{ }^{\circ} \mathrm{C}$ (blue line), and $3 \mathrm{D}-\mathrm{FTO}$ prepared at $550{ }^{\circ} \mathrm{C}$ (pink line). The deposition time for the $3 \mathrm{D}$-FTO samples was $25 \mathrm{~min}$.

FTO material prepared at $500{ }^{\circ} \mathrm{C}$, and the $3 \mathrm{D}$-FTO material prepared at $550{ }^{\circ} \mathrm{C}$. It was found that a further increase in temperature to $550{ }^{\circ} \mathrm{C}$ led to a preferential growth of the (101) planes, rendering pyramidal polyhedra with high aspect ratios. The preferred orientation along specific planes in $\mathrm{SnO}_{2}$ thin films was already reported back in 1996 by Muramaki et al., ${ }^{31}$ with deposition temperatures ranging from 340 to 480 ${ }^{\circ} \mathrm{C}$. In their work, it was found that the organometallic precursor type had a major impact on the grain orientation. However, the relatively low deposition temperatures employed resulted in limited knowledge about the temperature influence on the grain growth. A more recent report by Haddad et al., ${ }^{22}$ employing aerosol chemical vapor deposition (CVD), identified different regimes in the nucleation and grain growth of $\mathrm{SnO}_{2}$ nanoneedles, which was directly related to the substrate temperature with similar morphologies as those reported in our work. It was observed that the aspect ratio of the $\mathrm{SnO}_{2}$ nanocolumns varied exponentially with temperature, obtaining the best results at $600{ }^{\circ} \mathrm{C}$. The activation energy for the growth of $\mathrm{SnO}_{2}$ columns was found to be $58.8 \mathrm{~kJ} / \mathrm{mol}$, and it was reported that the main driving variable controlling the final dimensions of the nanocolumns was the substrate temperature.

Our results are in agreement with the nanostructured morphology reported by Haddad et al. ${ }^{22}$ However, in our experiments, it was observed that the growth along the (101) and (301) planes of the cassiterite structure was dominant, as evidenced in Figure 1. This difference could be attributed to the presence of $\mathrm{NH}_{4} \mathrm{~F}$ during the synthesis of our samples as previously reported by Elangovan et al., ${ }^{21}$ although further research should be conducted to determine the influence of the fluorine precursor on the final orientations. In contrast, commercial TEC 15 FTO shows a very smooth surface with preferred orientations along the (110) and (200) planes. Clearly, when the substrate temperature during deposition was kept at $450{ }^{\circ} \mathrm{C}$, the XRD pattern was very similar to that of TEC 15 FTO. Gradually increasing the substrate temperature showed a significant impact on the grain size and the crystallographic orientations. Unfortunately, our setup could not reach temperatures above $550{ }^{\circ} \mathrm{C}$. However, we would expect an increase in the aspect ratio as reported by Haddad et $\mathrm{al}^{22}$ at even higher temperatures.

To further understand the influence of reaction time, a series of samples were prepared, changing the deposition duration from 15 to $35 \mathrm{~min}$. Figure S4 shows SEM fresh cross sections of three 3D-FTO samples prepared at $550{ }^{\circ} \mathrm{C}$ during $15 \mathrm{~min}$ (a), $20 \mathrm{~min}$ (b), and $25 \mathrm{~min}$ (c). While already after $15 \mathrm{~min}$ of reaction the formation of nanopyramids was visible, the growth along the height and base was proportional during the first 35 min. To compare the relative increase in surface area with increasing deposition time, double-layer capacitive current plots are presented in Figure S5. The capacitive current in the tested samples reaches its maximum value after $35 \mathrm{~min}$ of deposition time. In addition, samples prepared after $35 \mathrm{~min}$ of reaction showed the best aspect ratio of the series with an average height of around $\sim 1 \mu \mathrm{m}$ and the base diameter varying from 250 to $500 \mathrm{~nm}$, as shown in Figure 2. The randomly oriented nanopyramid arrays showed mostly very sharp terminations at the tip, whereas some of the nanopyramids have an open/unfinished structure.

UV-vis spectroscopy measurements on commercial TEC 15 and 3D-FTO samples deposited on fused silica were performed in the transmission mode in the spectral range 350-750 nm. For comparison purposes, Figure $\mathrm{S} 6$ shows the transmittance of a 3D-FTO sample prepared after $25 \mathrm{~min}$ reaction at $550{ }^{\circ} \mathrm{C}$ on fused silica versus the transmittance of a commercial FTO TEC 15. On average, the nanostructured samples presented a $\sim 25 \%$ lower transmittance at $400 \mathrm{~nm}$, whereas at wavelengths beyond $600 \mathrm{~nm}$, similar values were obtained. It is worth noting that the samples prepared directly on fused silica presented a very thin compact layer with much higher sheet resistance when compared with samples prepared on commercial FTO. This can be explained by the rapid nucleation of smaller FTO islands on top of the amorphous fused silica that leads to thinner nanopyramids, as can be seen in Figure S7. For that reason, all electrochemical studies in this 


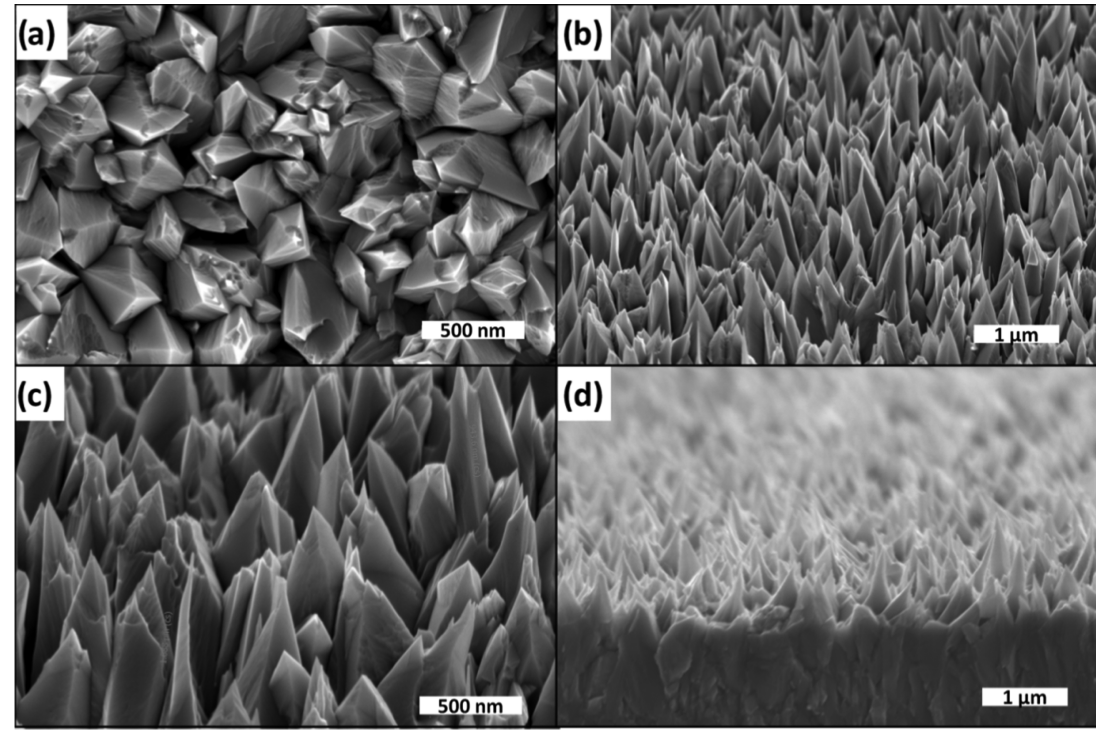

Figure 2. Scanning electron microscopy (SEM) images of a 3D-FTO sample prepared at $550{ }^{\circ} \mathrm{C}$ and 35 min deposition time. (a) Top view, (b) and (c) $52^{\circ}$ tilted view, and (d) fresh cross section view.
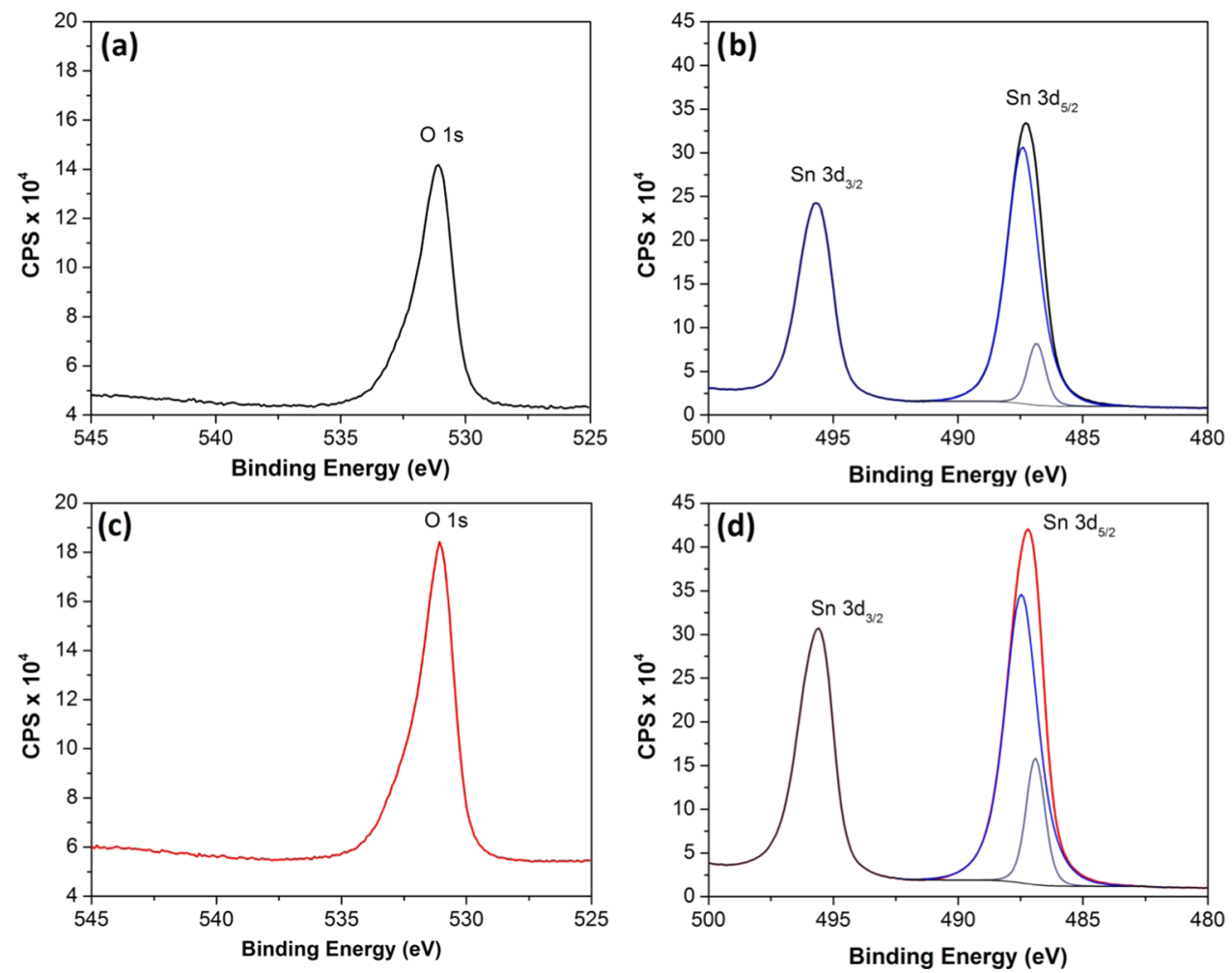

Figure 3. (a) and (b) X-ray photoelectron spectroscopy (XPS) data for the $\mathrm{O} 1 \mathrm{~s}$ and $\mathrm{Sn} 3 \mathrm{~d}$ edges of a $3 \mathrm{D}$-FTO sample prepared at $550{ }^{\circ} \mathrm{C}$ during 35 min. (c) and (d) XPS data for the $\mathrm{O} 1 \mathrm{~s}$ and Sn 3d edges of a commercial TEC 15 FTO sample.

work were realized employing nanostructured samples deposited on commercial FTO.

The series resistance from the scaffold interface with the current collector can contribute negatively to the final photocurrents. As the nanopyramid 3D-FTO was directly grown on top of commercial FTO TEC 15, a possible change in the sheet resistance could be the origin of a change in the performance of the photoelectrodes. To rule out the possibility of very different conductivities between the prepared 3D-FTO and commercial FTO, a four-point probe analysis was carried out on planar and nanostructured samples. The resistivity data, summarized in Figure S8, indicates that there is a noticeable difference between the nanostructured and planar samples, the latter being about 4 times more resistive. The sheet resistance observed for the commercial TEC 15 sample was $14.47 \Omega /$ sq, which is in agreement with the specifications of the supplier. The lower value of $3.75 \Omega /$ sq for the nanostructured sample is to be expected due to the noticeably thicker film in the nanostructured samples, as higher FTO thickness is known to improve conductivity. ${ }^{32,33}$ While commercial TEC 15 FTO 
shows an average thickness of $380 \pm 15 \mathrm{~nm}$, the nanostructured FTO samples grown directly on commercial FTO present a much higher base thickness ranging from 850 to 950 nm. Given that the charge carrier mobility and electrical conductivity in FTO are directly proportional to crystallite size and layer thickness, contrary to what happens with other types of nanostructured scaffolds, our USP-prepared FTO scaffold not only serves as a high-area substrate and current collector but also decreases the final sheet resistance of the photoelectrode. It is also worth mentioning that the resistance of the samples after annealing treatment in the oven at $750{ }^{\circ} \mathrm{C}$ for 15 min did increase a few ohms, which is similar to what happens with commercial TEC 15 samples. However, the heating and cooling ramps must be carefully controlled as the nanostructured FTO samples are prone to form cracks.

A study of the surface chemistry of nanostructured 3D-FTO scaffolds and commercial FTO was done by means of X-ray photoelectron spectroscopy (XPS). Figure 3 shows the corelevel spectra of the $\mathrm{O} 1 \mathrm{~s}$ and $\mathrm{Sn} 3 \mathrm{~d}$ edges of a 3D-FTO scaffold (panels a and b) prepared after $35 \mathrm{~min}$ at $550{ }^{\circ} \mathrm{C}$ and a commercial TEC 15 FTO substrate (panels $\mathrm{c}$ and d). Fluorine (F 1s edge) could not be detected at the surface of both samples, which suggests a low F doping level of the FTO films. The $\mathrm{O} 1 \mathrm{~s}$ binding energies of both samples are the same (binding energy $(\mathrm{BE})=531.1 \mathrm{eV}$ ). The $\mathrm{Sn} 3 \mathrm{~d}_{5 / 2} \mathrm{BE}$ values are also the same at 487.3 and $487.2 \mathrm{eV}$ for the nanostructured and commercial samples, respectively (spin-orbit splitting of $8.4 \mathrm{eV})$. The Sn 3d core spectral lines show distinctly asymmetric profiles, similar to those found in related conducting oxide systems including $\mathrm{PbO}_{2-x}{ }^{34} \mathrm{Sn}_{\mathrm{x}} \mathrm{In}_{2-x} \mathrm{O}_{3}{ }^{35}$ and $\mathrm{Sb}_{x} \mathrm{Sn}_{1-x} \mathrm{O}_{2} \cdot{ }^{36}$ The XPS spectra may be fitted with two Voigt components, as shown in Figure 3. The high-BE component is the broader of the two and has a predominant Lorentzian contribution to the line shape. Two alternative approaches have been used to describe this type of line shape. According to a model developed by Kotani and Toyozawa, ${ }^{37}$ the low-BE component corresponds to a final state where the core hole is screened by localization of a mobile conduction electron, whereas the high-BE component corresponds to a lifetime broadened unscreened final state.

Alternatively, it was recently shown that the high-BE component can be described as an unusually strong plasmon satellite resulting from a coupling of the $\mathrm{Sn}$ core hole to the plasma oscillations of the free electrons introduced by doping. ${ }^{38}$ A similar asymmetry can be observed in the $\mathrm{O} 1 \mathrm{~s}$ level, which, however, might also be due to the presence of spectrally overlapping hydroxyl and carbonate groups on the surface.

According to the obtained data from the XPS analysis, the surface chemistry of the nanostructured and commercial TEC 15 FTO samples is very similar. However, one of the direct consequences of the high aspect ratio obtained with these nanopyramid morphologies is an increase of surface area and different exposed crystalline facets of the substrate. This difference in surface termination could be a source of potential point defects leading to interfacial electron-hole recombination. Therefore, a comprehensive analysis of the exposed crystalline facets and surface groups should be undertaken in future studies.

From the information obtained with the different characterization methods (XRD, SEM, and XPS), we should expect similar electronic properties on both $3 \mathrm{D}-\mathrm{FTO}$ substrates and commercial FTO samples. The main difference is the higher aspect ratio and lower sheet resistance in our 3D-FTO samples compared to commercial FTO. It should be noted that the sheet resistance is lower due to the thickness of our 3D-FTO samples, which is roughly 2.5 times higher than that of commercial FTO.

3.2. Electrocatalytic Performance Testing. The thermodynamic potential for the OER is $E_{\mathrm{OER}}^{\circ}=+1.23 \mathrm{~V}_{\mathrm{RHE}}$. However, the implication of surface kinetics and intermediate reactions, such as the hydrogen peroxide formation, leads to higher values. For instance, commercial FTO shows a high overvoltage of around $500 \mathrm{mV}$ leading to poor OER activity. Figure $4 \mathrm{a}$ shows a sweep voltammetry comparison between a
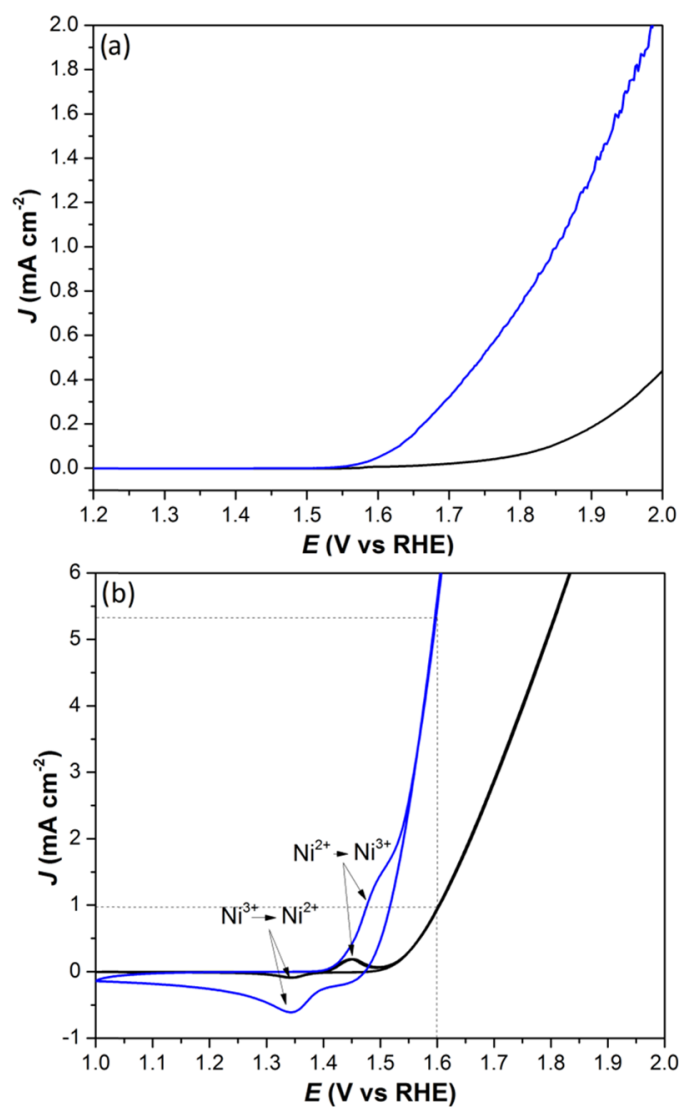

Figure 4. (a) Linear sweep voltammetry of a bare 3D-FTO (blue line) and a bare commercial TEC 15 FTO (black line). (b) cyclic voltammograms (5th repetition) of the $\mathrm{Ni}_{(1-x)} \mathrm{Fe}_{x}(\mathrm{OH})_{2}$ electrocatalyst prepared after 40 successive ionic layer adsorption and reaction (SILAR) cycles on 3D-FTO (blue line) and commercial TEC 15 FTO (black line). The scan rate is $10 \mathrm{mV} / \mathrm{s}$ in $1 \mathrm{M} \mathrm{NaOH}$ electrolyte.

commercial FTO electrode and an optimized 3D-FTO sample prepared after $35 \mathrm{~min}$ at $550{ }^{\circ} \mathrm{C}$. Not only the current onset potential is lower for the nanostructured sample but also the current density at $2 \mathrm{~V}_{\mathrm{RHE}}$ is about 5 times higher. This could be attributed to two aspects. First, the surface area of the nanostructured sample is higher. Second, the presence of different crystalline facets and/or defects exposed to the electrolyte may aid the catalytic performance.

Recently, we have demonstrated in our lab the fabrication of a very active and amorphous ultrathin $\mathrm{Ni}_{(1-x)} \mathrm{Fe}_{x}(\mathrm{OH})_{2}$ OER catalyst prepared by successive ionic layer adsorption and reaction (SILAR). ${ }^{39}$ Employing the SILAR technique, we have managed to conformally coat both the nanostructured and 


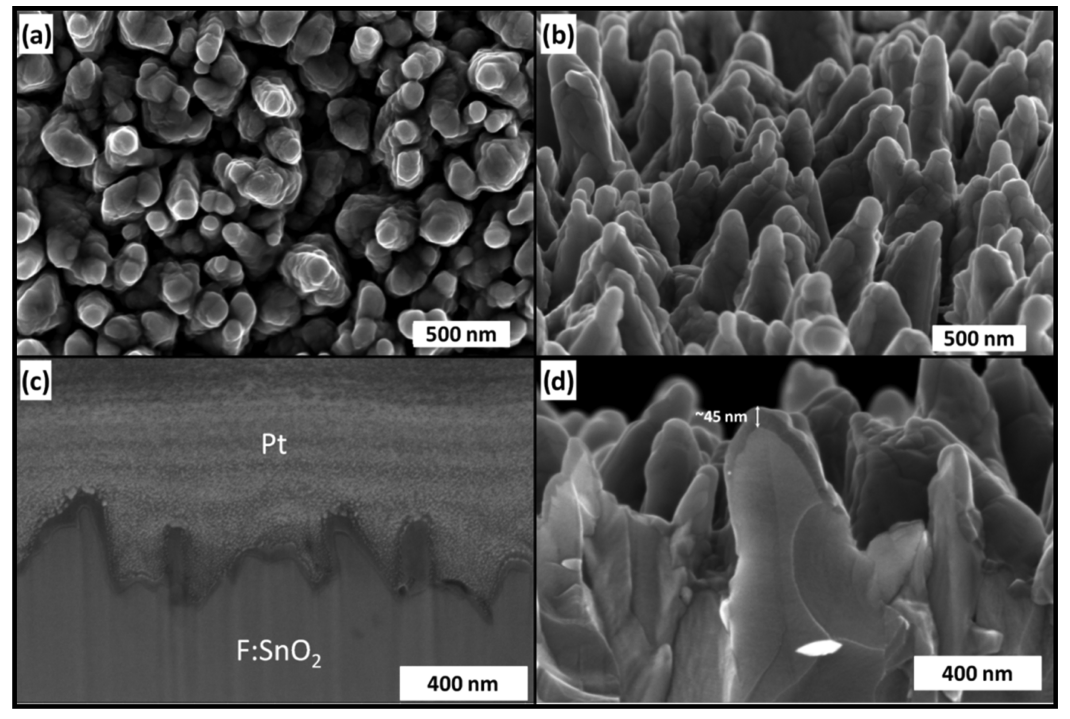

Figure 5. Scanning electron microscopy (SEM) images of a $\sim 45 \mathrm{~nm}$ hematite photoanode deposited by USP (120 cycles) on 3D-FTO. (a) Top view, (b) $52^{\circ}$ tilted view, (c) focused ion beam (FIB)-SEM cross section of the sample, and (d) fresh cross section of the same sample immersed in liquid $\mathrm{N}_{2}$ for $10 \mathrm{~s}$ and mechanically fractured in two pieces.
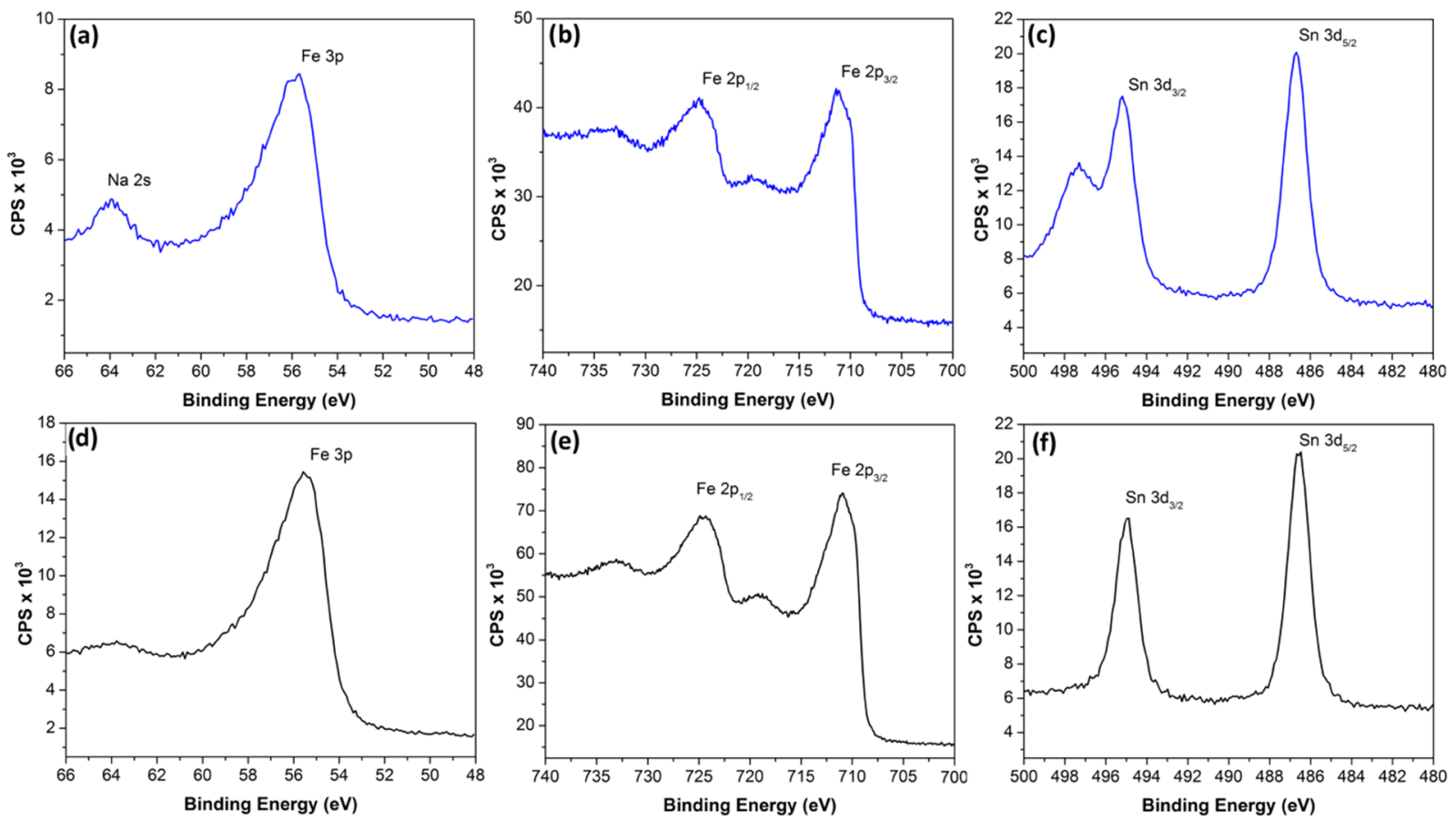

Figure 6. (a), (b), and (c) X-ray photoelectron spectroscopy (XPS) data of the Fe 3p, Fe 2p, and Sn 3d edges, respectively, obtained from hematite samples deposited on 3D-FTO heat-treated at $750{ }^{\circ} \mathrm{C}$ for $15 \mathrm{~min}$. (d), (e), and (f) X-ray photoelectron spectroscopy (XPS) data of the Fe 3p, Fe $2 \mathrm{p}$, and Sn 3d edges, respectively, obtained from hematite samples deposited on commercial FTO heat-treated at $750{ }^{\circ} \mathrm{C}$ for 15 min.

commercial FTO substrates with a $\sim 20 \mathrm{~nm}$ thick layer of amorphous $\mathrm{Ni}_{(1-x)} \mathrm{Fe}_{x}(\mathrm{OH})_{2}$ catalyst. Figure $4 \mathrm{~b}$ shows cyclic voltammetry of the same samples as in Figure $4 \mathrm{a}$ after being coated with a $\sim 20 \mathrm{~nm}$ thick $\mathrm{Ni}_{(1-x)} \mathrm{Fe}_{x}(\mathrm{OH})_{2}$ catalyst by SILAR. Clearly, the onset potential for the OER in both samples coated with $\mathrm{Ni}_{(1-x)} \mathrm{Fe}_{x}(\mathrm{OH})_{2}$ is very similar with a difference of less than $50 \mathrm{mV}$. However, the linear part of the voltammogram for the nanostructured sample shows current densities about 5 times higher than that of the commercial sample. In addition, the nickel reduction peaks shown in the cathodic direction of the cyclic voltammetry present a much higher area for the nanostructured samples. Given that now we are looking exclusively at the OER activity of the amorphous $\mathrm{Ni}_{(1-x)} \mathrm{Fe}_{x}(\mathrm{OH})_{2}$ catalyst, we may conclude that the main reason for the higher activity in the nanostructured samples is strictly related to the higher surface area presented by the high aspect ratio of the nanopyramid arrays.

To gain some knowledge about the influence of the nanostructured scaffolds on the photoelectrochemical performance of metal-oxide photoelectrodes, hematite was selected as a good example of photoabsorber given its very low carrier mobility and simple preparation. It should be pointed out that the hematite samples tested in this work were undoped and their thickness was not optimized for maximum performance. 
They serve merely as a proof of concept leaving much room for optimization. For the synthesis of hematite films on commercial TEC 15 FTO and nanostructured 3D-FTO substrates, vertical USP was employed. As we are interested in studying the effect of the higher surface provided by the $3 \mathrm{D}$ FTO substrates, we have decided to keep the hematite layer thickness close to the calculated space charge layer ${ }^{7}$ at $\sim 45 \mathrm{~nm}$ or 120 USP cycles. The SEM image in Figure S9a corresponds to a top view of a hematite thin film deposited on commercial FTO and annealed at $550{ }^{\circ} \mathrm{C}$ for $2 \mathrm{~h}$ and at $750{ }^{\circ} \mathrm{C}$ for $15 \mathrm{~min}$, whereas the SEM image in Figure S9b shows a cross section of the same sample employing focused ion beam-scanning electron microscopy (FIB-SEM) where a $300 \mathrm{~nm}$ Pt coating was used as the protective layer. Hematite films deposited on planar commercial FTO substrates were highly conformal and crack free with an average thickness of $\sim 50 \mathrm{~nm}$ along the whole sample surface. When the same USP process for hematite deposition was employed on 3D-FTO substrates, the conformality along the cross section of the nanopyramids was very heterogeneous. While the tips of the nanostructures presented an average hematite thickness between 45 and 50 $\mathrm{nm}$, the coating at the bottom part of the nanopyramids was found to be ranging from 15 to $30 \mathrm{~nm}$ in the majority of the observed samples. The SEM images of Figure 5 offer a good example of the average morphology obtained for a 120 USP cycles hematite film annealed at $550^{\circ} \mathrm{C}$ for $2 \mathrm{~h}$ and $750{ }^{\circ} \mathrm{C}$ for $15 \mathrm{~min}$.

Given that the nanopyramid arrays are randomly oriented, it was very complicated to obtain reliable thickness measurements employing FIB-SEM, as observed in Figure 5c. However, fresh cross sections of the samples revealed a clear change in the hematite layer thickness along the profile of the nanostructures, as shown in Figure 5d. We should emphasize that due to the uneven thickness of the hematite coatings on 3D-FTO substrates, the performance comparison between the planar and nanostructured photoanodes prepared by USP is only approximate. Clearly, further research work employing conformal coating deposition techniques, such as atomic layer deposition (ALD), must be used to fully estimate the real gain in performance due to the nanostructured scaffold. Nevertheless, every sample examined in this work presented a continuous hematite coating without exposing any cracks or patches of FTO to the electrolyte.

To further study the difference in surface chemistry between the planar and nanostructured photoelectrodes, XPS analysis was employed in samples annealed at $750{ }^{\circ} \mathrm{C}$ for 15 min after electrochemical testing, as depicted in Figure 6. Although no dopants were used for the preparation of hematite photoanodes in this work, unintentional doping with Sn species diffusing from the substrate can be expected after annealing at high temperature. ${ }^{40}$ However, the $\mathrm{Sn} / \mathrm{Fe}$ ratio in the nanostructured samples obtained from the XPS survey spectra was much higher ( 11 atom \% Sn) than that of the planar counterpart ( 3 atom \% Sn). This difference could be attributed to the lack of conformality of the hematite film thickness shown in the FIB-SEM cross sections of the nanostructured samples. The chemical state of $\mathrm{Fe}$, though, was very similar in both samples ( $\mathrm{Fe} 2 \mathrm{p}_{3 / 2}$ XPS peaks at 724.5 and $724.3 \mathrm{eV}$ for the nanostructured and planar sample, respectively). These values are typical for $\mathrm{Fe}_{2} \mathrm{O}_{3}{ }^{41}$ The slight shift to higher $\mathrm{BE}$ values for the nanostructured sample is also observed for the $\mathrm{Fe} 3 \mathrm{p}, \mathrm{Sn} 3 \mathrm{~d}$, and $\mathrm{O} 1 \mathrm{~s}$ edges (see Figure S10) and can accordingly be attributed to a higher n-type doping of the nanostructured sample. A higher concentration of unintentional Sn-doping increases the n-type doping and therefore brings the chemical potential (i.e., Fermi level) of the $\mathrm{Fe}_{2} \mathrm{O}_{3}$ closer to the conduction band. As XPS is referred to the Fermi level of the samples, an increase of the Fermi-level energy results in a shift of the core lines to higher BE values. In addition, the $\mathrm{Na} 2 \mathrm{~s}$ XPS peak at $63.9 \mathrm{eV}$ can be clearly observed in the nanostructured sample, which indicates that despite careful cleaning with abundant distilled water after electrochemical testing, $\mathrm{Na}$ traces from the electrolyte (1 M $\mathrm{NaOH}$ ) still remain at the surface.

The large difference in $\mathrm{Sn}$ surface concentration between nanostructured and planar hematite could have an important impact on their respective performances. As mentioned above, the nonconformal nature of the hematite coating onto the nanostructured FTO substrates leads to areas with very thin hematite layers of roughly $\sim 15 \mathrm{~nm}$ in thickness, whereas planar hematite shows a continuous layer of about $\sim 50 \mathrm{~nm}$. The effect of surface $\mathrm{Sn}$ in planar hematite samples annealed at 800 ${ }^{\circ} \mathrm{C}$ for 13.5 min was studied by Shinde et al. ${ }^{42}$ In their work, it was reported that planar hematite samples presenting a $\mathrm{Sn} /(\mathrm{Fe}$ $+\mathrm{Sn}$ ) surface content of 9.3 atom \% showed an increase of $37 \%$ in photocurrent (at $1.23 \mathrm{~V}$ vs RHE) when compared to samples with a surface $\mathrm{Sn} /(\mathrm{Sn}+\mathrm{Fe})$ content of 4.9 atom \%. Moreover, in a follow-up paper from the same research group, it was determined that high $\mathrm{Sn}$ contents at the surface of hematite samples resulted in important anodic shifts for the onset photocurrents due to the formation of a resistant $\mathrm{SnO}_{x}$ layer. ${ }^{43}$ Given that the hematite layer thickness in some regions of the nanostructured samples is close to the depth sensitivity of the XPS measurement, it is reasonable to assume that the thinnest layers might show higher Sn contents, leading to a heterogeneous Sn surface distribution. Angle-resolved XPS can provide detailed chemical as well as depth profile information about the near-surface composition of thin films. ${ }^{44,45}$ Table S1 summarizes the $\mathrm{Sn} / \mathrm{Fe}$ ratio obtained at take-off angles (ToA) $\theta 90^{\circ}$ and $\theta 10^{\circ}$ for the nanostructured and planar photoanodes. It is worth noting that the Sn distribution in the nanostructured sample is very broad, especially at a ToA of $90^{\circ}$.

To confirm the higher effective light absorbance from the nanostructured samples, UV-vis-NIR spectroscopy was employed. As expected, the hematite-coated 3D-FTO substrate exhibits a much higher light absorption compared to the planar sample, especially at longer wavelengths. Figure S11 shows the stronger light-harvesting effect of the nanostructured hematite photoanode (blue line) compared to the planar version (black line). From the SEM images of Figure 5, the largest distance between the tips of two neighboring nanopyramids can be estimated between 400 and $500 \mathrm{~nm}$, which together with their random orientation facilitate the scattering effect, thus enhancing the light absorption. Despite the significant enhancement in light absorption of the nanostructured samples, with near-unity absorption values at wavelengths below $600 \mathrm{~nm}$, the lack of conformality in the hematite coating makes it very difficult to draw a clear conclusion about the photoelectrochemical performance enhancement. It is important to note that the improvement of light absorption comes at a price, given that the total transmittance is drastically reduced when our nanostructured substrate was employed as can be seen in Figure S12. Nevertheless, further work optimizing the direct growth of 3D-FTO directly onto fused silica substrates must be carried out to explore the use of our nanopyramid 

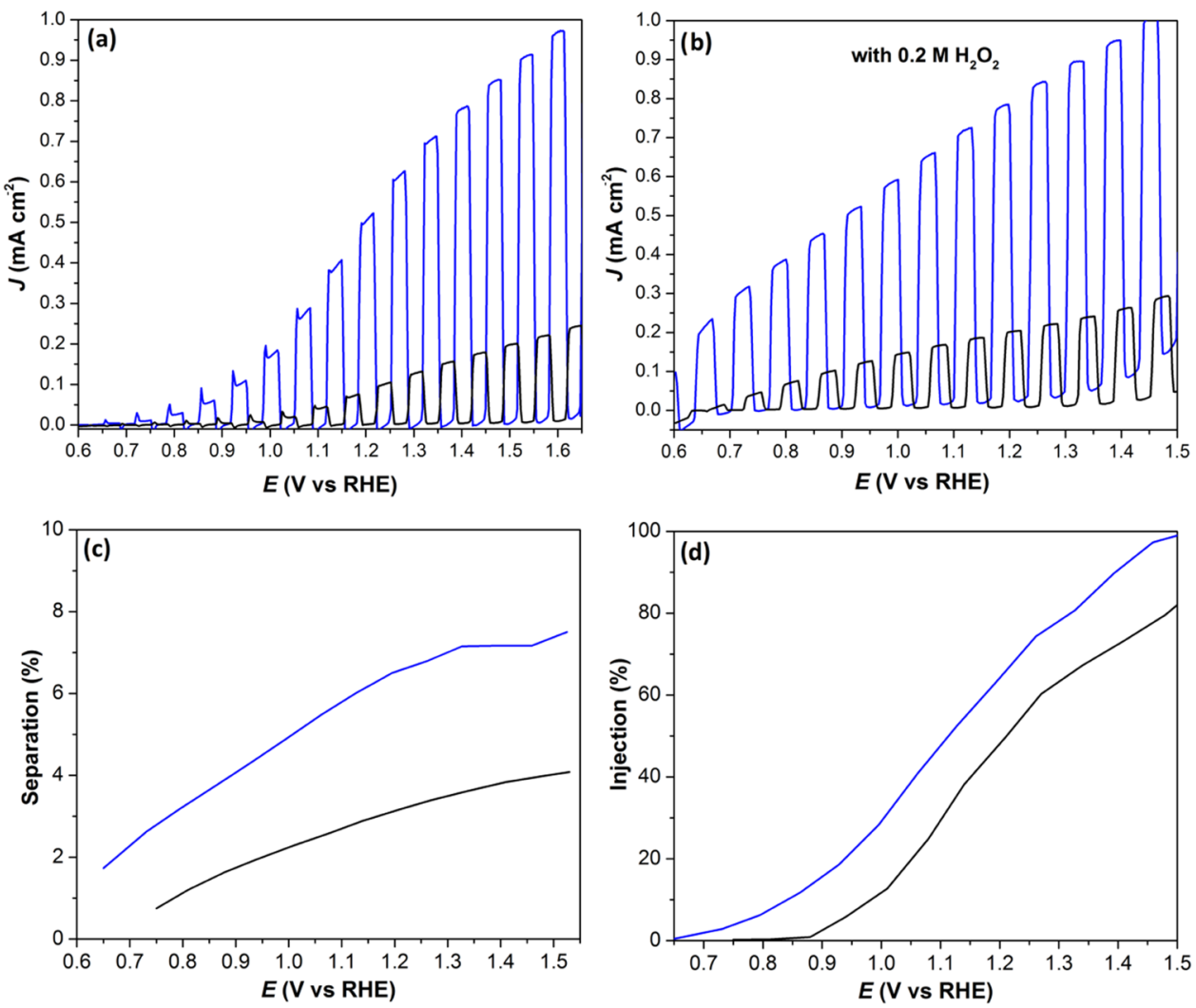

Figure 7. (a) Chopped light sweep voltammograms of a $50 \mathrm{~nm}$ thick hematite film on commercial FTO (black) and a nonconformal ca. $~ 45 \mathrm{~nm}$ hematite film deposited on 3D-FTO (blue line). (b) Chopped light sweep voltammograms of the same set of samples as in (a) after the addition of $0.2 \mathrm{M} \mathrm{H}_{2} \mathrm{O}_{2}$ in the electrolyte solution. (c) Yield of charge separation for nanostructured hematite (blue line) and $50 \mathrm{~nm}$ thick planar hematite (black line). (d) Yield of charge injection for nanostructured hematite (blue line) and planar hematite (black line). The electrolyte was $1 \mathrm{M} \mathrm{NaOH}$. The scan rate was $20 \mathrm{mV} / \mathrm{s}$, and 1 sun illumination with a $1.5 \mathrm{AM}$ filter was shone from the electrolyte/hematite side (front illumination).

structure in tandem systems, where light transmission is much more relevant.

Chopped light linear sweep voltammetry (AM 1.5 simulated illumination) was employed to observe the impact of the nanostructured scaffold on the performance of hematite photoanodes. To compare the water oxidation onset potentials, $V_{\text {on }}$, from the obtained photoelectrochemical data, we followed the report by Le Formal et al. ${ }^{46}$ in which the $V_{\text {on }}$ was defined as the potential where the slope, $\mathrm{d} J / \mathrm{d} V$, is $0.20 \times 10^{-3} \mathrm{~mA} \mathrm{~cm}^{-2}$ $\mathrm{mV}^{-1}$, showing a $150 \mathrm{mV}$ lower onset potential for the nanostructured samples in the sweep voltammogram of Figure 7a. Compared to the planar version (black line), comprising a conformal $50 \mathrm{~nm}$ thick hematite layer, hematite photoanodes deposited on 3D-FTO substrates (blue line) showed a 4.5-fold improvement of the photocurrents at $1.23 \mathrm{~V}$ vs RHE. This impressive gain in photoelectrochemical performance was attributed to the much higher surface area of the high-aspectratio nanostructured scaffold. However, as mentioned earlier, the change in the hematite layer thickness ranging from $\sim 15$ $\mathrm{nm}$ in the thinnest points up to $\sim 45 \mathrm{~nm}$ at the tips of the nanopyramids makes it difficult to compare the planar versus the nanostructured samples.

Another source of important performance differences between the planar and nanostructured samples may be due to different surface terminations and Sn species concentration. Although we have no evidence from XRD due to the ultrathin nature of the hematite films, the different crystal orientation from the nanostructured support compared to the commercial FTO, together with the different Sn concentration along the hematite thickness, could induce a preferential growth of certain crystallographic planes, leading to a distinct concentration of surface states as previously reported. ${ }^{47}$

To further investigate whether photocurrent is mainly limited by charge separation or hole injection, chopped linear sweep voltammetries were performed in a $1 \mathrm{M} \mathrm{NaOH}$ and 0.2 $\mathrm{M} \mathrm{H}_{2} \mathrm{O}_{2}$ electrolyte. Figure $7 \mathrm{~b}$ shows the photoelectrochemical performance of a planar $50 \mathrm{~nm}$ sample (black line) and a 3DFTO sample (blue line) in a $1 \mathrm{M} \mathrm{NaOH}$ electrolyte with $0.2 \mathrm{M}$ $\mathrm{H}_{2} \mathrm{O}_{2}$. Without the influence of charge transfer limitations, a photocurrent is obtained at all potentials due to the oxidation of hydrogen peroxide. The nanostructured samples showed an average gain of $\sim 285 \%$ in photocurrent versus the $50 \mathrm{~nm}$ planar samples at $1.23 \mathrm{~V}$ vs RHE.

To estimate the role that the different surface concentrations of $\mathrm{Sn}$ and crystal lattice orientation might play in the charge separation and injection, we have investigated the photoelectrochemical performance of the planar and nanostructured samples during the much simpler $\mathrm{H}_{2} \mathrm{O}_{2}$ oxidation, as first described by Dotan et al. ${ }^{48}$ Here, the water splitting photocurrent $\left(J_{\mathrm{ph}}\right)$ can be described as

$$
J_{\mathrm{ph}}=J_{\mathrm{abs}} \times \eta_{\mathrm{sep}} \times \eta_{\text {inj }}
$$

were $J_{\mathrm{abs}}$ is the photon absorption rate expressed as current density (assuming APCE $100 \%$ ), $\eta_{\text {sep }}$ is the charge separation efficiency within the bulk of the film, and $\eta_{\text {inj }}$ is the efficiency of the hole injection from the semiconductor to the electrolyte. By adding to the electrolyte $0.2 \mathrm{M} \mathrm{H}_{2} \mathrm{O}_{2}$, a well-known hole 

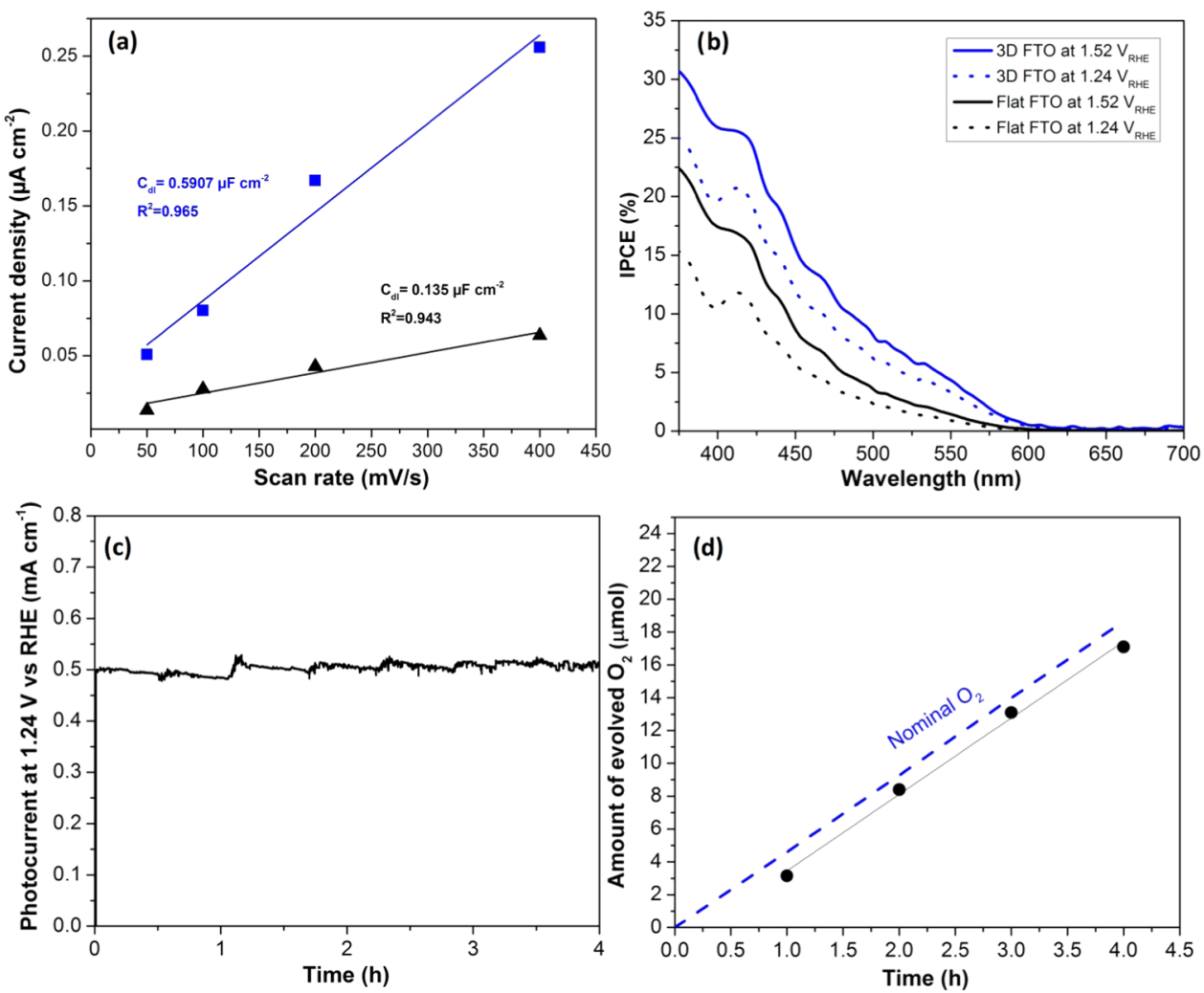

Figure 8. Photoelectrochemical water splitting with hematite photoanodes. (a) Capacitive current densities extracted from the cyclic voltammetries at $+1.10 \mathrm{~V}$ vs RHE plotted against the scan rate. The slope of the regression lines represents the capacitance of the 3D-FTO samples (blue line) and the flat FTO samples (black line). (b) Incident photon-to-current conversion efficiency (IPCE) of an $80 \mathrm{~nm}$ thick planar hematite sample (black line) compared to that of nanostructured hematite on 3D-FTO (blue line). (c) Chronoamperometry of a nanostructured hematite sample at $1.24 \mathrm{~V}$ vs RHE. (d) Faradaic efficiency measurement of a nanostructured hematite photoanode under simulated 1 sun illumination in a $1 \mathrm{M} \mathrm{NaOH}$ electrolyte. The straight line corresponds to the integration of the net photocurrent divided by 4, which corresponds to an FE of $100 \%$. The black dots correspond to $\mathrm{O}_{2}$ gas measured with gas chromatography.

scavenger, $\eta_{\text {inj, }}$ can be assumed as unity. Therefore, $\eta_{\text {inj }}$ and $\eta_{\text {sep }}$ can be obtained according to

$$
\eta_{\text {inj }} \frac{J_{\mathrm{ph}}^{\mathrm{H}_{2} \mathrm{O}}}{J_{\mathrm{ph}}^{\mathrm{H}_{2} \mathrm{O}_{2}}} \text { and } \eta_{\text {sep }} \frac{J_{\mathrm{ph}}^{\mathrm{H}_{2} \mathrm{O}_{2}}}{J_{\mathrm{abs}}}
$$

Figure $7 \mathrm{c}$ shows the potential-dependent $\eta_{\text {sep }}$ for a nanostructured hematite sample (blue line) and a planar $50 \mathrm{~nm}$ thick hematite sample (black line). In both cases, $\eta_{\text {sep }}$ increases with applied potential as the depletion width increases. This is more noticeable in the nanostructured sample, which reaches a plateau at around $1.35 \mathrm{~V}$ vs RHE. However, $\eta_{\text {sep }}$ is very low in both samples, reaching at $1.52 \mathrm{~V}$ vs RHE a maximum of 7.5 and $4.0 \%$ for the nanostructured and planar samples, respectively. Charge separation is therefore a significant limitation of the photocurrent, although the nanostructured sample showed an $\eta_{\text {sep }}$ improvement of roughly $100 \%$ at $1.23 \mathrm{~V}$ vs RHE when compared to the planar sample.

Potential-dependent $\eta_{\text {inj }}$ is plotted in Figure $7 \mathrm{~d}$ for both the nanostructured and planar hematite samples. At low applied potentials, $\eta_{\text {inj }}$ is negligible and increases with increasing anodic potentials in a similar manner for both the planar and nanostructured samples, reaching 52 and $68 \%$, respectively, at $1.23 \mathrm{~V}$ vs RHE. The injection yield rises with applied potential up to more than $80 \%$ for the planar sample and close to $100 \%$ in the case of the nanostructured hematite at $1.5 \mathrm{~V}$ vs RHE. Interestingly, both samples show a similar slope in the potential-dependent charge injection efficiency, which is an indication of similar charge transfer kinetics taking place at the surface of the electrodes. The thinner hematite layer in the nanostructured photoanode results in less bulk recombination, as seen in the $\eta_{\text {sep }}$ plot of Figure $7 \mathrm{c}$, and more holes are able to reach the electrode/electrolyte interface compared to the planar electrode.

Mott-Schottky analysis was performed to gain further insight into the role of $\mathrm{Sn}$ in the water splitting reaction. Figure S13 shows Mott-Schottky plots at $100 \mathrm{~Hz}$ with $1 \mathrm{M} \mathrm{NaOH}$ electrolyte for planar and nanostructured hematite photoanodes (Figure S13a,b, respectively). A $0.05 \mathrm{~V}$ shift to lower potential was observed in flat band potential $\left(V_{\mathrm{fb}}\right)$ of the nanostructured sample compared to the planar version, which could explain the better injection efficiency and $V_{\text {on }}$ of the former.

Although initially the origin of the higher photocurrents obtained with the nanostructured samples was attributed primarily to the increase of surface provided by the 3D-FTO scaffolds, the contribution of the hematite layer thickness and surface defects should be taken into account. To estimate the relative difference in the surface area between the planar and nanostructured photoanodes, double-layer capacitance measurements were performed in $1 \mathrm{M} \mathrm{NaOH}$ electrolyte, assuming that the only difference between the samples is the surface area. Figure 8 a summarizes the capacitive current densities at different scan rates from nanostructured (in blue) and planar (black) hematite photoanodes (cyclic voltammetries are provided in Figure S14). From the slope of the regression 
lines, the double-layer capacitance can be compared for both types of electrodes. The nanostructured version shows a capacitance about $\sim 4.4$ times higher than that of the planar photoanode, which could be directly translated to a relative increase in the roughness factor, assuming the same material properties, and thus the same specific capacitance, in both electrodes. This observed increase in the relative surface for the nanostructured samples is in agreement with the relative increase in anodic currents for the samples coated with the amorphous $\mathrm{Ni}_{(1-x)} \mathrm{Fe}_{x}(\mathrm{OH})_{2}$ catalyst.

To further verify the photocurrent improvement, incident photon-to-current conversion efficiencies (IPCEs) were measured for the $3 \mathrm{D}-\mathrm{FTO} / \alpha-\mathrm{Fe}_{2} \mathrm{O}_{3}$ nanopyramid electrode and a planar $\mathrm{FTO} / \alpha-\mathrm{Fe}_{2} \mathrm{O}_{3}$ electrode as a function of the wavelength. Figure $8 \mathrm{~b}$ reveals that the nanostructured photoanode has a remarkably enhanced visible light response compared to the planar version. This enhancement increases at higher wavelengths being 1.5 times higher at $400 \mathrm{~nm}$ and 3 times higher at $550 \mathrm{~nm}$, demonstrating the important benefit provided by the nanostructured FTO scaffold in agreement with the $J-V$ curves in Figure 7. At wavelengths beyond 600 $\mathrm{nm}$, the photoresponse of both samples drops to zero, as expected from the band gap of $\alpha-\mathrm{Fe}_{2} \mathrm{O}_{3}$. The strong enhancement observed on the nanostructured sample could be ascribed to the increase in surface area as well as enhanced light absorption and improved charge separation, although given the lack of conformality of the hematite films, it remains difficult to understand the extent of the enhanced absorption contribution.

It is well known from the literature that under the adequate electrolyte conditions, $\alpha$ - $\mathrm{Fe}_{2} \mathrm{O}_{3}$ photoelectrodes can drive the water splitting reaction with Faradaic efficiencies close to unity. ${ }^{49}$ To verify that the measured photocurrents originate from the water splitting and not from photodegradation or any undesired side reactions, gas chromatography was employed for a period of $4 \mathrm{~h}$. The anodic photocurrent obtained during the polarization at $1.24 \mathrm{~V}$ vs RHE is presented in Figure $8 \mathrm{c}$, whereas the amount of evolved $\mathrm{O}_{2}$ gas as a function of time is shown in Figure 8d. For this measurement, the data were recorded after a stabilization period of $1 \mathrm{~h}$. The total amount of $\mathrm{O}_{2}$ obtained indicates a Faradaic efficiency of $\sim 94 \%$ with virtually no degradation in the photoperformance during the duration of the experiment.

\section{CONCLUSIONS}

Fluorine-doped tin oxide (FTO) nanopyramids were successfully prepared using a simple template-free bottom-up approach employing the inexpensive and highly scalable ultrasonic spray pyrolysis (USP) technique. By controlling the substrate temperature and reaction time, the aspect ratio of the nanostructures obtained can be tuned, obtaining the best results after $35 \mathrm{~min}$ of reaction at $550{ }^{\circ} \mathrm{C}$. The resulting FTO nanostructured scaffolds deposited on fused silica show a $25 \%$ lower transmittance at $400 \mathrm{~nm}$ compared to the commercial FTO samples and similar resistivity. The viability of the nanostructured scaffolds for their application in water splitting was demonstrated, employing the active $\mathrm{Ni}_{(1-x)} \mathrm{Fe}_{x}(\mathrm{OH})_{2}$ OER catalyst prepared by SILAR. The photoelectrochemical performance of thin hematite coatings prepared by the USP method was also studied. Compared to the planar version, nanostructured hematite photoanodes showed a much higher photocurrent, an observation which was mainly attributed to an increase in the surface area. Our results indicate that the high-aspect-ratio FTO nanopyramids employed as scaffolds help increasing the optical absorbance of the photoactive semiconductor while allowing for the use of ultrathin semiconductor coatings with effective photogenerated charge collection. Thus, decoupling light absorption and charge transfer can be carried out with proper tuning of the surface area and layer thickness of the light absorber.

\section{ASSOCIATED CONTENT}

\section{S Supporting Information}

The Supporting Information is available free of charge on the ACS Publications website at DOI: 10.1021/acsami.9b05176.

UV-vis spectra; sheet resistance measurements; SEM micrographs of intermediate reaction steps; and scheme of in-house-built spray pyrolysis setup (PDF)

\section{AUTHOR INFORMATION}

\section{Corresponding Author}

*E-mail: b.m.weckhuysen@uu.nl.

ORCID

Jan P. Hofmann: 0000-0002-5765-1096

Emiel J. M. Hensen: 0000-0002-9754-2417

Bert M. Weckhuysen: 0000-0001-5245-1426

\section{Author Contributions}

The manuscript was written through contributions of all authors. All authors have given approval to the final version of the manuscript.

Notes

The authors declare no competing financial interest.

\section{ACKNOWLEDGMENTS}

We acknowledge financial support from the Netherlands Center for Multiscale Catalytic Energy Conversion (MCEC). The authors would like to also acknowledge doctoral candidate Shashank Balasubramanyam (TU/e) for his help with the film resistivity measurements.

\section{REFERENCES}

(1) Du, C.; Yang, X.; Mayer, M. T.; Hoyt, H.; Xie, J.; McMahon, G.; Bischoping, G.; Wang, D. Hematite-Based Water Splitting with Low Turn-On Voltages. Angew. Chem., Int. Ed. 2013, 52, 12692-12695.

(2) Morales-Guio, C. G.; Mayer, M. T.; Yella, A.; Tilley, S. D.; Graetzel, M.; Hu, X. An Optically Transparent Iron Nickel Oxide Catalyst for Solar Water Splitting. J. Am. Chem. Soc. 2015, 137, 99279936.

(3) Sivula, K.; Le Formal, F.; Graetzel, M. Solar Water Splitting: Progress Using Hematite $\left(\alpha-\mathrm{Fe}_{2} \mathrm{O}_{3}\right)$ Photoelectrodes. ChemSusChem 2011, 4, 432-449.

(4) Kennedy, J. H.; Frese, K. W., Jr. Photooxidation of Water at $\alpha$ $\mathrm{Fe}_{2} \mathrm{O}_{3}$ Electrodes. J. Electrochem. Soc. 1978, 125, 709-714.

(5) Abdi, F. F.; Savenije, T. J.; May, M. M.; Dam, B.; van de Krol, R. The Origin of Slow Carrier Transport in $\mathrm{BiVO}_{4}$ Thin Film Photoanodes: A Time-Resolved Microwave Conductivity Study. J. Phys. Chem. Lett. 2013, 4, 2752-2757.

(6) Balberg, I.; Pinch, H. L. The Optical Absorption of Iron Oxides. J. Magn. Magn. Mater. 1978, 7, 12-15.

(7) Klahr, B. M.; Martinson, A. B. F.; Hamann, T. W. Photoelectrochemical Investigation of Ultrathin Film Iron Oxide Solar Cells Prepared by Atomic Layer Deposition. Langmuir 2011, 27, 461-468.

(8) van de Krol, R.; Liang, Y.; Schoonman, J. Solar Hydrogen Production with Nanostructured Metal Oxides. J. Mater. Chem. 2008, $18,2311-2320$. 
(9) Ling, Y.; Wang, G.; Wheeler, D. A.; Zhang, J. Z.; Li, Y. Sn-Doped Hematite Nanostructures for Photoelectrochemical Water Splitting. Nano Lett. 2011, 11, 2119-2125.

(10) Beermann, N.; Vayssieres, L.; Lindquist, S.; Hagfeldt, A. Photoelectrochemical Studies of Oriented Nanorod Thin Films of Hematite. J. Electrochem. Soc. 2000, 147, 2456-2461.

(11) Brillet, J.; Graetzel, M.; Sivula, K. Decoupling Feature Size and Functionality in Solution-Processed, Porous Hematite Electrodes for Solar Water Splitting. Nano Lett. 2010, 10, 4155-4160.

(12) Kay, A.; Cesar, I.; Graetzel, M. New Benchmark for Water Photooxidation by Nanostructured $\alpha-\mathrm{Fe}_{2} \mathrm{O}_{3}$ Films. J. Am. Chem. Soc. 2006, 128, 15714-15721.

(13) Sivula, K.; Le Formal, F.; Graetzel, M. $\mathrm{WO}_{3}-\mathrm{Fe}_{2} \mathrm{O}_{3}$ Photoanodes for Water Splitting: A Host Scaffold, Guest Absorber Approach. Chem. Mater. 2009, 21, 2862-2867.

(14) Müller, A.; Kondofersky, I.; Folger, A.; Fattakhova-Rohlfing, D.; Bein, T.; Scheu, C. Dual Absorber $\mathrm{Fe}_{2} \mathrm{O}_{3} / \mathrm{WO}_{3}$ Host-guest Architectures for Improved Charge Generation and Transfer in Photoelectrochemical Applications. Mater. Res. Express 2017, 4, No. 016409.

(15) Abel, A. J.; Garcia-Torregrosa, I.; Patel, A. M.; Opasanont, B.; Baxter, J. B. SILAR-Deposited Hematite Films for Photoelectrochemical Water Splitting: Effects of Sn, Ti, Thickness, and Nanostructuring. J. Phys. Chem. C 2015, 119, 4454-4465.

(16) Wang, L.; Palacios-Padros, A.; Kirchgeorg, R.; Tighineanu, A.; Schmuki, P. Enhanced Photoelectrochemical Water Splitting Efficiency of a Hematite-Ordered $\mathrm{Sb}: \mathrm{SnO}_{2}$ Host-Guest System. ChemSusChem 2014, 7, 421-424.

(17) Riha, S. C.; Klahr, B. M.; Tyo, E. C.; Seifert, S.; Vajda, S.; Pellin, M. J.; Hamann, T. W.; Martinson, A. B. F. Atomic Layer Deposition of a Sub-Monolayer Catalyst for the Enhanced Photoelectrochemical Performance of Water Oxidation with Hematite. ACS Nano 2013, 7, 2396-2405.

(18) Tang, M. H.; Chakthranont, P.; Jaramillo, T. F. Top-down Fabrication of Fluorine-Doped Tin Oxide Nanopillar Substrates for Solar Water Splitting. RSC Adv. 2017, 7, 28350-28357.

(19) Banyamin, Z. Y.; Kelly, P. J.; West, G.; Boardman. Electrical and Optical Properties of Fluorine Doped Tin Oxide Thin Films Prepared by Magnetron Sputtering. Coatings 2014, 4, 732-746.

(20) Kumara, G. R. A.; Ranasinghe, C. S. K.; Jayaweera, E. N.; Bandara, H. M. N.; Okuya, M.; Rajapakse, R. M. G. Preparation of Fluoride-Doped Tin Oxide Films on Soda-Lime glass Substrates by Atomized Spray Pyrolysis Technique and Their Subsequent Use in Dye-Sensitized Solar Cells. J. Phys. Chem. C 2014, 118, 16479-16485.

(21) Elangovan, E.; Ramamurthi, K. Studies on Micro-structural and Electrical Properties of Spray-Deposited Fluorine-doped Tin Oxide Thin Films from Low-Cost Precursor. Thin Solid Films 2005, 476, 231-236.

(22) Haddad, K.; Abokifa, A.; Kavadiya, S.; Chadha, T. S.; Shetty, P.; Wang, Y.; Fortner, J.; Biswas, P. Growth of Single Crystal, Oriented $\mathrm{SnO}_{2}$ Nanocolumn Arrays by Aerosol Chemical Vapour Deposition. CrystEngComm 2016, 18, 7544-7553.

(23) Li, X.; Wang, X.; Shen, Q.; Zheng, J.; Liu, W.; Zhao, H.; Yang, F.; Yang, H. Controllable Low-Temperature Chemical Vapor Deposition Growth and Morphology Dependent Field Emission Property of $\mathrm{SnO}_{2}$ Nanocone Arrays with Different Morphologies. ACS Appl. Mater. Interfaces 2013, 5, 3033-3041.

(24) Vayssieres, L.; Graetzel, M. Highly Ordered $\mathrm{SnO}_{2}$ Nanorod Arrays from Controlled Aqueous Growth. Angew. Chem., Int. Ed. 2004, 43, 3666-3670.

(25) Wang, X.; Liu, W.; Yang, H.; Li, X.; Li, N.; Shi, R.; Zhao, H.; $\mathrm{Yu}$, J. Low-temperature Vapor-Solid Growth and Excellent Field Emission Performance of Highly Oriented $\mathrm{SnO}_{2}$ Nanorod Arrays. Acta Mater. 2011, 59, 1291-1299.

(26) Cho, C.; Lee, J.; Riu, D.; Kim, C. Fast Responsive Gas Sensor of Vertically Aligned Fluorine-Doped Tin Oxide Nanorod Thin Film. Jpn. J. Appl. Phys. 2012, 51, No. 045001.
(27) Oshima, M.; Yoshino, K. Thickness Dependence of Structure and Optical Characteristics in Fluorine-Doped $\mathrm{SnO}_{2}$ Films Grown by Spray Pyrolysis Method. Jpn. J. Appl. Phys 2012, 51, No. 125503.

(28) Liyanage, D.; Mudiyanselage, H.; Bandara, N.; Jayaweera, V.; Murakami, K. Ethylene Glycol Assisted Synthesis of Fluorine Doped Tin Oxide Nanorods Using Improved Spray Pyrolysis Deposition Method. Appl. Phys. Express 2013, 6, No. 085501.

(29) Bandara, A.; Murakami, K.; Rajapaks, R. M. G.; Jayaweera, P. V. V.; Shimomura, M.; Bandara, H. M. N.; Liyanage, D.; Premalal, E. V. A. Versatile Synthesis of Fluorine-Doped Tin (IV) Oxide Onedimensional Nanostructured Thin Films. Thin Solid Films 2017, 621, 229-239.

(30) Wang, K. X.; Yu, Z.; Liu, V.; Brongersma, M. L.; Jaramillo, T. F.; Fan, S. Nearly Total Solar Absorption in Ultrathin Nanostructured Iron Oxide for Efficient Photoelectrochemical Water Splitting. ACS Photonics 2014, 1, 235-240.

(31) Murakami, K.; Yagi, I.; Kaneko, S. Oriented Growth of Tin Oxide Thin Films on Glass Substrates by Spray Pyrolysis of Organotin Compounds. J. Am. Ceram. Soc. 1996, 79, 2557-2562.

(32) Amanullah, F. M.; Pratap, K. J.; Babu, V. H. Thickness Dependence of Electrical and Structural Properties of FTO Films. Cryst. Res. Technol. 1991, 26, 1099-1105.

(33) Oshima, M.; Yoshino, K. Thickness Dependence of Structure and Optical Characteristics in Fluorine-Doped $\mathrm{SnO}_{2}$ Films Grown by Spray Pyrolysis Method. Jpn. J. Appl. Phys. 2012, 51, No. 125503.

(34) Payne, D. J.; Egdell, R. G.; Hao, W.; Foord, J. S.; Walsh, A.; Watson, G. W. Why is Lead Dioxide Metallic? Chem. Phys. Lett. 2005, $411,181-185$.

(35) Bourlange, A.; Payne, D. J.; Palgrave, R. G.; Zhang, H.; Foord, J. S.; Egdell, R. G.; Jacobs, R. M. J.; Veal, T. D.; King, P. D. C.; McConville, C. F. The Influence of Sn Doping on theGrowth of $\operatorname{In}_{2} \mathrm{O}_{3}$ on Y-Stabilized $\mathrm{ZrO}_{2}(100)$ by Oxygen Plasma Assisted Molecular Beam Epitaxy. J. Appl. Phys. 2009, 106, No. 013703.

(36) O’Neila, D. H.; Egdell, R. G.; Edwards, P. P. Surface Composition and Electronic Structure of the $\mathrm{In}_{4+\mathrm{x}} \mathrm{Sn}_{3-2 \mathrm{x}} \mathrm{Sb}_{\mathrm{x}} \mathrm{O}_{12}(0$ $\leq \times \leq 1$ ) Solid Solution. J. Appl. Phys. 2010, 107, No. 093702 .

(37) Kotani, A.; Toyozawa, Y. Photoelectron Spectra of Core Electrons in Metals with an Incomplete Shell. J. Phys. Soc. Jpn. 1974, 37, 912-919.

(38) Borgatti, F.; Berger, J. A.; Céolin, D.; Zhou, J. S.; Kas, J. J.; Guzzo, M.; McConville, C. F.; Offi, F.; Panaccione, G.; Regoutz, A.; Payne, D. J.; Rueff, J. P.; Bierwagen, O.; White, M. E.; Speck, J. S.; Gatti, M.; Egdell, R. G. Revisiting the Origin of Satellites in Core-level Photoemission of Transparent Conducting Oxides: The Case of $\mathrm{n}$ doped $\mathrm{SnO}_{2}$. Phys. Rev. B 2018, 97, No. 155102.

(39) Garcia-Torregrosa, I.; Goryachev, A.; Hofmann, J. P.; Hensen, E. J. M.; Weckhuysen, B. M. Efficient and Highly Transparent UltraThin Nickel-Iron Oxy-hydroxide Catalyst for Oxygen Evolution Prepared by Successive Ionic Layer Adsorption and Reaction. ChemPhotoChem 2019, DOI: 10.1002/cptc.201900131.

(40) Morrish, R.; Rahman, M.; Don MacElroy, J. M.; Wolden, C. A. Activation of Hematite Nanorod Arrays for Photoelectrochemical Water Splitting. ChemSusChem 2011, 4, 474-479.

(41) Biesinger, M. C.; Paynec, B. P.; Grosvenor, A. P.; Laua, L. W. M.; Gersonb, A. R.; Smart, R. StC. Resolving Surface Chemical States in XPS Analysis of First Row Transition Metals, Oxides and Hydroxides: Cr, Mn, Fe, Co and Ni. App. Surf. Sci. 2011, 257, 2717-2730.

(42) Shinde, P. S.; Annamalai, A.; Kim, J. H.; Choi, S. H.; Lee, J. S.; Jang, J. S. Exploiting the Dynamic Sn Diffusion from Deformation of FTO to Boost the Photocurrent Performance of Hematite Photoanodes. Sol. Energy Mater. Sol. Cells 2015, 141, 71-79.

(43) Shinde, P. S.; Sun, H. C.; Kim, Y.; Ryu, J.; Jang, J. S. Onset Potential Behavior in $\alpha-\mathrm{Fe}_{2} \mathrm{O}_{3}$ Photoanodes: The Influence of Surface and Diffusion Sn Doping on the Surface States. Phys. Chem. Chem. Phys. 2016, 18, 2495-2509.

(44) Iijima, J.; Lim, J. W.; Hong, S. H.; Suzuki, S.; Mimura, K.; Isshiki, M. Native Oxidation of Ultra High Purity $\mathrm{Cu}$ Bulk and Thin Films. Appl. Surf. Sci. 2006, 253, 2825-2829. 
(45) Gulino, A.; Condorelli, G. G.; Fragalh, I.; Egdell, R. G. Surface Segregation of $\mathrm{Sb}$ in Doped $\mathrm{TiO}_{2}$ Rutile. Appl. Surf. Sci. 1995, 90, 289-295.

(46) Le Formal, F.; Grätzel, M.; Sivula, K. Controlling Photoactivity in Ultrathin Hematite Films for Solar Water-Splitting. Adv. Funct. Mater. 2010, 20, 1099-1107.

(47) Liu, T.; Zhou, X.; Dupuis, M.; Li, C. The Nature of Photogenerated Charge Separation Among Different Crystal Facets of $\mathrm{BiVO}_{4}$ Studied by a Density Functional Theory. Phys. Chem. Chem. Phys. 2015, 17, 23503-23510.

(48) Dotan, H.; Sivula, K.; Graetzel, M.; Rothschild, A.; Warren, S. C. Probing the Photoelectrochemical Properties of Hematite (a$\mathrm{Fe}_{2} \mathrm{O}_{3}$ ) Electrodes Using Hydrogen Peroxide as a Hole Scavenger. Energy Environ. Sci. 2011, 4, 958-964.

(49) Lindgren, T.; Vayssieres, L.; Wang, H.; Lindquist, S. Photooxidation of Water at Hematite Electrodes. In Chemical Physics of Nanostructured Semiconductors; CRC Press: Boca Raton, 2003; pp $83-110$.

\section{NOTE ADDED AFTER ASAP PUBLICATION}

This paper was published on the Web on September 30, 2019, with minor text errors on page $G$ of the document. The corrected version was reposted on October 9, 2019. 